\title{
Telework and perceived workload: Learnings prior to the COVID-19 upheaval
}

\author{
Tuuli Turja ${ }^{\mathrm{a}, *}$, Oxana Krutova ${ }^{\mathrm{b}}$ and Harri Melin ${ }^{\mathrm{a}}$ \\ ${ }^{a}$ Faculty of Social Sciences, Tampere University, Tampere, Finland \\ ${ }^{\mathrm{b}}$ Finnish Institute of Occupational Health, Helsinki, Finland
}

Received 8 October 2021

Accepted 9 December 2021

\begin{abstract}
During COVID-19, telework has become a new form of work for broader groups of workers who were not teleworking prior to the pandemic. In this study, we ask what we will be returning to after COVID-19, if teleworking will become a new norm or if most workplaces will merely return to the old forms of work. The main research question of this study was to estimate the role of telework in perception of workload. More specifically, to gain an understanding of the stakes involved when reorganizing work after the pandemic, we analysed the relationship between perceived workload and opportunities to telework. Multilevel analysis utilized representative national data of wage earners in Finland $(\mathrm{N}=4091)$. The findings showed that the opportunity to telework is associated with lower perceived workload in the capital area but not in the rural areas. More specifically, increasing telework opportunities among different-level workers, particularly in educational and social work in the capital area, would be beneficial in terms of increasing well-being at work. There could be good reasons for organizations to reject returning to the status quo ex ante after COVID-19 and to consider the new norm, where opportunities to telework are offered to wider worker groups.
\end{abstract}

Keywords: COVID-19 exit, telework, well-being, workload

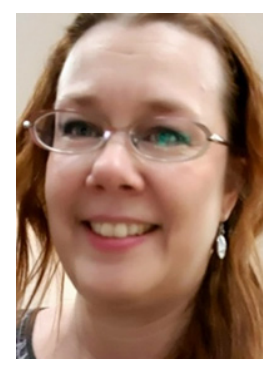

Tuuli Turja is a postdoc researcher in Tampere University. After two decades in personnel administration, Turja changed her career into research, and focuses now on social and motivation psychology of changing work. Turja is especially interested in studying the myths in robotizing and technologizing work.

${ }^{*}$ Corresponding author: Tuuli Turja, Faculty of Social Sciences,

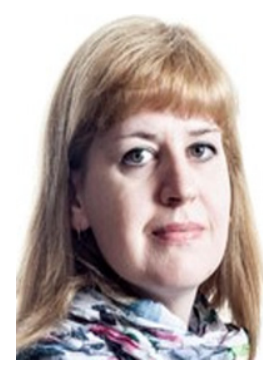

Oxana Krutova $(\mathrm{PhD})$ studies segmentation of labour markets, immigrants and technological unemployment using advanced methods with comparative and longitudinal data.

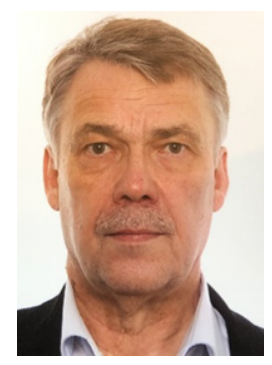

Harri Melin is a professor of sociology who has a prominent history in the field of working life studies and topics such as power relations, flexible work and digitalization. 


\section{Introduction}

During the worldwide pandemic and physical distancing, telework has emerged almost a new, although perhaps temporary, norm in certain occupations and fields of work. COVID-19 caused telework, not only to intensify in occupations where it had already been used, but also reached new fields of work. Previously, telework was typically offered to employees in two scenarios: for someone with an established and trusted status in the workplace or for virtual workers considered a group separated from the work community [1]. However, all these quite opposite positions seemed to be levelled when COVID-19 made telework a norm in every field of work in which it was possible to be organized.

The challenge for management is to maintain job satisfaction also in changing situations [2]. In this study, we analysed how the opportunity to telework is reflected in the perceived physiological and psychological workload in different fields of work and in different regions of the country prior to the pandemic. The question is, are there implications that especially in some contexts, rather than others, the new norm of telework should be considered by the management? The goal of this study was to estimate the role of telework in perception of workload. Representative national Finnish wage earners' data was used to analyse the research question and the question of who would benefit the most from teleworking opportunity as an indefinite new form of work after COVID-19.

\subsection{Telework}

Telework refers to paid work that is done outside the premises of the employer in a mutual agreement. Telework includes jobs one could also execute on the employer's premises; hence, doing mobile work (e.g., as a courier) or work on a customer's premises are not considered telework. The nature of the occupation is an obvious factor in defining the possibility for teleworking. Whereas the majority of office work can be moved into a home environment, there are many fields of work that do not have this option. European statistics show how telework has been most common in financial services, public administration, and education [3].

After the COVID-19 upheaval, telework quickly became an opportunity to increase flexibility and autonomy for broader groups of employees. For example, in Finland, the share of employees who were teleworking doubled from about $30 \%$ to about $60 \%$ [4, p. 63]. The question is, after the pandemic, should we actually ever go back to the status quo ex ante? A U.S. study found that perceived stress decreased a $10 \%$ among the white-collar workers who started working at home during the pandemic [5]. In Europe, it was found that workers experienced less fatigue and felt more engaged with their job in MayJune 2020 compared with just before COVID-19 [6]. Thus, we hypothesize that teleworking opportunity is associated with a lower level of perceived workload.

\subsection{Macro-level factors of telework}

In addition to occupational factors, there are more environmental and structural factors that play a part in enabling or restricting telework. Telework is more common in urban or suburban than in rural areas [7, 8]. This is partly linked to the occupational factor because white-collar jobs are concentrated in urban growth centres $[8,9]$. The frequency of teleworking contracts among regions in the country can be explained by the varying inhabitant density and commuting conditions. These factors refer to the social environment that varies in how the infrastructure supports telework.

Although new technology has been a major factor in enabling teleworking in home offices, telework is not a new invention per se. For example, the oil crisis in the $1970 \mathrm{~s}$ initiated the search for alternatives to daily commuting, and telework was viewed as one of the potential solutions [10]. In a similar vein, in the $2000 \mathrm{~s}$, the environmental effects of commuting and decreasing traffic have been among the top priorities in rationalizing telework [11]. Another priority is regarding cost- and time-effectiveness and how travelling time between home and work can be used in a more productive way if one does not have to leave home. Work commuting is considered time lost, and a longer duration of commute is associated with a higher level of commuting stress [12].

Several things make Finland a model country for teleworking. First, Finland is a technologically advanced and highly networked country [7]. Second, Finland was one of the first countries to implement telework as a supplement to normal working, which has been explained by the social environment of trust and low power distances [13] between employers and employees. Furthermore, work commuting has 
a significant role in Finland as a relatively sparsely populated country. Telework has been more common in Finland than in similar Nordic countries and cultures such as Sweden, Norway, and Denmark or in the U.S. [14]. Finnish regions differ in population density and public transfer, and Finland is a good example of a country that has variation between longer distances between home and work and shorter but more time-consuming work travelling [15].

This study focuses on the micro and macro level in telework and perceived workload. Hence, the meso level of organizational attributes and factors is excluded as a research topic that has received more attention than studies on occupational groups and the societal infrastructure.

\section{Data and methods}

This study used the Finnish Quality of Work Life (FQWL) data collected by Statistics Finland in 2018, before COVID-19. The data includes national interview data and provides a large and representative sample of Finnish wage earners $(\mathrm{N}=4091 ; 52 \%$ female; average age 44.22). Of the respondents, 7.7\% had a basic education, while the rest were divided between those having a college degree $(40.8 \%)$ and those with a higher education than that $(51.3 \%)$. The analysis also utilized open data published by Statistics Finland to retrieve information about region-level statistics and population densities.

\subsection{Main variables}

In the response variable of subjective workload, we used a summary variable $(\mathrm{M}=4.55, \mathrm{SD}=1.06$, $\mathrm{Md}=4.00$, 2-item range 2-8), which estimates both the physical and the mental strain of work. The minimum (2) means the lowest level of perceived workload, while the maximum (8) means the highest level of perceived workload.

Teleworking was inquired about in a question of three categories. The majority $(66.6 \%)$ of the respondents reported never having teleworked, whereas $29.4 \%$ reported teleworking in their current employment and $4.1 \%$ reported prior teleworking experience.

Regions were a categorical variable including either all the 16 regions available in the data or dichotomized into the capital region of Uusimaa and other regions in Finland. Of the respondents who worked in the capital area, $45 \%$ reported teleworking. Only $22 \%$ of respondents outside the capital area reported teleworking.

The largest occupational groups in the data worked in the business sector $(n=1150)$ or in the industrial, construction and transportation sectors $(n=970)$ followed by professionals in healthcare $(n=687)$, professionals in technology or science $(n=682)$ and professionals in education, social work and legislation $(n=600)$.

\subsection{Statistical procedures}

The multilevel modelling was based on two-step, two-level analyses. The hierarchical nature of the FQWL data allowed us to perform multilevel analysis, whereby individual workers were nested in regions. This was important for the assumption that individuals in the same region have similar characteristics and sociocultural attributes. According to the analysis, we surmised that random effects (including workload at the macro level) and fixed effects (telework, education, age, gender, and occupation at the micro level, and capital area at the macro level) affect the workload differently depending on the region.

\section{Results}

In the data from 2018, 29\% of the respondents reported having an agreement on teleworking. In the descriptive analysis, the opportunity to telework was found to be associated mostly with the male gender, $\chi^{2}(1)=6.21 ; p<0.05$, those with higher education, $\chi^{2}(2)=416.54 ; p<0.001$, and working in the capital region, $\chi^{2}(1)=232.52, p<0.001$. Those who teleworked in their current employment found work on average less burdening $(\mathrm{M}=4.2 ; \mathrm{SD}=0.95)$ than those not teleworking $(\mathrm{M}=4.7 ; \mathrm{SD}=1.08)$, $\mathrm{F}(1)=166.80 ; p<0.001$.

We examined how the perceived workload is associated with teleworking opportunities while adding individual-level factors of occupation, education, age, and gender and a level of working region (Table 1). A non-existing opportunity to telework was associated with higher perceived workload and, hence, gave some support to our hypothesis. This was, however, true only in the capital area. The association between telework and lower workload depended on the region. The workers who were not teleworking 
Table 1

Perceived workload and teleworking among Finnish workers

\begin{tabular}{|c|c|}
\hline \multicolumn{2}{|l|}{ Perceived workload } \\
\hline Intercept & $4.017^{* * *}(0.134)$ \\
\hline \multicolumn{2}{|l|}{ Telework (ref. = Yes) } \\
\hline Not at the moment & $-0.081(0.140)$ \\
\hline Never & $0.277^{* * *}(0.059)$ \\
\hline \multicolumn{2}{|l|}{ Education (ref. = Basic education) } \\
\hline College degree & $0.038(0.062)$ \\
\hline Higher education & $-0.259^{* * *}(0.066)$ \\
\hline \multicolumn{2}{|l|}{ Age (ref. = 15-24) } \\
\hline $25-34$ & $0.245^{* *}(0.077)$ \\
\hline $35-44$ & $0.264^{* * *}(0.076)$ \\
\hline $45-54$ & $0.242^{* *}(0.075)$ \\
\hline $55-64$ & $0.223^{* *}(0.076)$ \\
\hline $65-67$ & $-0.092(0.202)$ \\
\hline \multicolumn{2}{|l|}{ Gender (ref. = Male) } \\
\hline Female & $0.072(0.037)$ \\
\hline \multicolumn{2}{|c|}{ Occupation (ref. = Highest management) } \\
\hline Technology & $-0.092(0.087)$ \\
\hline Healthcare & $0.652^{* * *}(0.094)$ \\
\hline Educational and social workers & $0.312^{* * *}(0.089)$ \\
\hline Business & $-0.114(0.086)$ \\
\hline Construction and transportation & $0.205(0.106)$ \\
\hline Manufacturing & $0.180(0.100)$ \\
\hline MISC & $0.305^{* *}(0.108)$ \\
\hline \multicolumn{2}{|l|}{ Region level (ref. $=$ Capital area) } \\
\hline Other regions & $0.209^{*}(0.079)$ \\
\hline \multicolumn{2}{|c|}{ Interaction between telework and region: } \\
\hline Never* Other regions & $-0.152^{*}(0.073)$ \\
\hline AIC & 11649.96 \\
\hline $\mathrm{BIC}$ & 11801.43 \\
\hline logLik & -5800.98 \\
\hline Number of Observations & 4091 \\
\hline Number of Groups (region) & 16 \\
\hline
\end{tabular}

and lived outside the capital region reported lower perceived workload.

As secondary findings, lower perceived workload was more likely among those with higher education, and a high perceived workload was reported most commonly in healthcare, education, and social work.

In the post-hoc analysis, teachers and social workers stood out with the highest and statistically significant interaction between perceived workload and the opportunity to telework. Interactions between opportunity to telework and region-level factors of higher population density and public transfer density did not reach any statistical significance in predicting the perceived workload.

\section{Discussion}

COVID-19 exit on the horizon, this study shows how an opportunity to telework would be beneficial to maintain as a new norm also after the pandemic. The benefits of teleworking are being highlighted among broad groups of workers instead of the typical teleworking jobs of those with a high education concentrated in the capital area.

To return to the status quo ex ante after the current situation with the pandemic would mean that many workers who were introduced to telework would be denied to continue the more flexible form of work. This change to old ways of working could also be viewed as increasing work stress and decreasing work engagement $[2,6]$. Furthermore, returning to the old would mean that teleworking regressed once again into being the privilege of employees of higher positions.

We turn to cultural explanations in our finding that higher perceived workload was associated with workers who had no opportunity to telework in an area where teleworking was generally most common. The fairness in telework policies in the workplaces is already acknowledged [16], and our results imply that this is also applicable in wider cultural settings. In regions where telework is culturally common, people may expect more flexible work for themselves, too.

Teaching and social work stood out as occupations that would benefit the most from more flexible arrangements and opportunities to telework. In particular, younger workers without an opportunity to telework reported higher levels of perceived workload compared to those with the opportunity to telework. Younger teachers and social workers reported higher perceived workload and are understood as an occupational group that would benefit from a future of more flexible work.

In conclusion, having an opportunity to telework decreases the perceived physical and psychological workload of an individual. The implication, hence, is that by adding opportunities to telework for wider demographics and worker groups in their COVID19 exit plans, management would make a strategic investment in the well-being of the employees. This would also be a step toward higher perceived and factual equality among workers.

\section{Acknowledgments}

This study was supported by The Finnish Work Environment Fund. 


\section{Author contributions}

CONCEPTION: Tuuli Turja and Harri Melin METHODOLOGY: Tuuli Turja and Oxana Krutova INTERPRETATION OR ANALYSIS OF DATA: Tuuli Turja and Oxana Krutova PREPARATION OF THE MANUSCRIPT: All authors

SUPERVISION: Harri Melin

\section{References}

[1] Even A. The evolution of work: Best practices for avoiding social and organizational isolation in telework employees. SSRN. 2020. doi:10.2139/ssrn.3543122

[2] Ahmed T, Shahid Khan M, Thitivesa D, Siraphatthada Y, Phumdara T. Impact of employees engagement and knowledge sharing on organizational performance: Study of HR challenges in COVID-19 pandemic. Hum. Syst. Manag. 2020;39(4):589-601. doi:10.3233/HSM-201052

[3] Eurofound [Internet]. Available from: https://www.euro found.europa.eu/news/news-articles/working-anytime-any where-the-effects-on-the-world-of-work-new-report-high lights-opportunities-and. [Accessed September 2021]

[4] Melin H, Turja T, Krutova O. Työelämän uusi normaali. [New normal in working life] Työpoliittinen aikakauskirja 3/2020. https://julkaisut.valtioneuvosto.fi/handle/10024/ 162481 .

[5] Bernstein E, Blunden H, Brodsky A, Sohn W, Waber B. The implications of working without an office. Harv. Bus. Rev. 2020; [Internet] Available from: https://hbr.org/ 2020/07/the-implications-of-working-without-an-office [Accessed September 2021]
[6] Hakanen J, Kaltiainen J. Miten Suomi voi. [How are you, Finland] Finnish Institution of Occupational Health. 2020; [Internet] Available from: https://www.ttl.fi/ tutkimushanke/miten-suomi-voi/ [Accessed May 2021]

[7] Pyöriä P. Managing telework: Risks, fears and rules. Manag. Res. Rev. 2011;34(4):386-99.

[8] Vilhelmson B, Thulin E. Who and where are the flexible workers? Exploring the current diffusion of telework in Sweden. New Technol Work Employ. 2016;31(1):77-96.

[9] Cooke P. Knowledge Economies: Clusters, Learning and Competitive Advantage. London: Routledge; 2002.

[10] Mamia T, Melin H. Tietoyhteiskunta ja työorganisaatioiden muutos. [Information society and organizational changes]; Sosiological Studies A30, University of Turku; 2007.

[11] Hook A, Sovacool BK, Sorrell S. A systematic review of the energy and climate impacts of teleworking. Environ. Res. Lett. 2020;15(9). doi:10.1088/1748-9326/ab8a84

[12] Gottholmseder G, Nowotny K, Pruckner GJ, Theurl E. Stress perception and commuting. Health Econ. 2009;18(5):559-76. doi:10.1002/hec.1389

[13] Pekkola J. Etätyö Suomessa. Fyysiset, virtuaaliset, sosiaaliset ja henkiset työtilat etätyöympäristöinä. [Telework in Finland. Physical, virtual, social and mental environments] Publications of the Swedish School of Economics and Business Administration. 2002;104. Helsinki.

[14] Bonnet F (Forthcoming). The home as workplace: Trends and policies for ensuring decent work. ILO.

[15] Novaco RW, Gonzales OI. Commuting and well-being. In: Amichai-Hamburger Y, editor. Technology and Psychological Well-being New York, NY: Cambridge University Press; 2009;174-205.

[16] Lee D, Kim SY. A quasi-experimental examination of telework eligibility and participation in the US federal government. Rev. Public Pers. Adm. 2018;38(4):451-71. 